\title{
MOBILIDADE ENTRE ESTADOS DE POBREZA E INSERÇÃO NO MERCADO DE TRABALHO: UMA ANÁLISE PARA O BRASIL METROPOLITANO EM 2004
}

\author{
Ana Flávia Machado ${ }^{\S}$ \\ Rafael Perez Ribas ${ }^{\prime \prime}$ \\ Mariângela Penido ${ }^{\dagger}$
}

\begin{abstract}
RESUMO
A relação entre dinâmica da pobreza e inserção no mercado de trabalho compreende questões como o que direciona certos grupos pobres a escaparem desta condição e o que induz outros grupos a entrarem na pobreza. Buscando analisar essas questões, o objetivo geral deste artigo é investigar a relação entre mobilidade entre estados de pobreza e forma de inserção no mercado de trabalho no Brasil metropolitano em 2004. Para o acompanhamento longitudinal dos indivíduos na amostra, a fim de captar a mobilidade, foi utilizada a Pesquisa Mensal de Emprego (PME) 2004 como fonte dos dados. O modelo de mobilidade, ou de transição na pobreza, é baseado em uma matriz de Markov, utilizando como estratégia para estimação um modelo probit com seleção amostral. A partir da observação do processo de mobilidade nesse modelo, foram calculadas taxas de permanência e de transição para a pobreza, assim como outras medidas de mobilidade, para cada grupo de condição ocupacional. Os resultados evidenciam a relevância da inserção ocupacional para permanência em estados de não-pobreza e transições para fora da pobreza.
\end{abstract}

Palavras-chave: pobreza, mercado de trabalho, mobilidade, matriz de Markov, dados longitudinais.

\begin{abstract}
The relation between dynamics of poverty and labor market includes some issues as what conducts certain poor groups to escape of this condition and what induces other groups to enter in the poverty. Seeking to analyze these issues, the purpose of this article is to investigate the relation between poverty states and way of occupational conditions in the labor market in Brazilian metropolitan areas in 2004. To follow up individuals in the sample, in order to hold the mobility, the Pesquisa Mensal de Emprego (PME) 2004 was used as source of the database. The model of mobility, or poverty transition model, is based on a Markov matrix, using as strategy of estimating a probit model with sample selection. Observing the mobility process in this model, poverty permanence rates and poverty transition rates had been calculated, as well as other mobility measurements, for each group of occupational condition. The results point out the importance of labor market aspects to permanence in the non-poor state and transitions to out of poverty.
\end{abstract}

Key words: poverty, labor market, mobility, Markov matrix, longitudinal data.

JEL Classification: C35, I32, J60.

$\S \quad$ Cedeplar/UFMG. E-mail: afmachad@cedeplar.ufmg.br.

a Cedeplar/UFMG e IPC-UNDP. E-mail: rafael.ribas@undp-povertycentre.org.

$\dagger$ Faculdade Arnaldo. E-mail: mariangela@faculdadearnaldo.com.br.

Endereço para contato: Rua Curitiba 832, sala 801 - Belo Horizonte - Minas Gerais.

Recebido em agosto de 2006. Aceito para publicação em maio de 2007. 


\section{INTRODUÇão}

No Brasil, a pesquisa sobre as causas e o comportamento da pobreza se intensifica a partir da segunda metade da década de 1990, quando a estabilização econômica implementada com o Plano Real retira de cena o problema inflacionário. Com isso, foi possível aprofundar uma agenda direcionada para as questões sociais, em especial, a incidência da pobreza. Os trabalhos publicados envolvem diversos aspectos da pobreza. Entre eles, há os que tratam de definição de linhas de pobreza e mensuração de pobres, como os de Rocha (2003) e Ferreira et al. (2003), da relação entre salário mínimo e pobreza, como os de Ramos e Reis (1995) e Camargo et al. (2001), do conceito de capacitações e análise qualitativa da pobreza, como os de Comim e Bagolin (2002), dos aspectos relacionados a causas da pobreza, desigualdade e exclusão social no Brasil, caso de Schwartzman (2004a e 2004b), das relações entre desigualdade e pobreza, como no artigo de Ferreira et al. (2006) e em alguns trabalhos compilados por Henriques (2000). Entretanto, há uma lacuna que reside justamente nos estudos sobre dinâmica da pobreza, principalmente estudos que relacionem esta dinâmica à inserção no mercado de trabalho.

Sobre o tema de mobilidade na pobreza, Ribas et al. (2005) estimaram as probabilidades de permanência e transição de estados numa matriz de Markov, por intermédio de um modelo probit bivariado com seleção endógena para dados agrupados por coortes da Pesquisa Nacional de Amostra por Domicílio (PNAD). Os resultados evidenciam um caráter essencialmente crônico da pobreza, estando mais sujeitos a este componente da pobreza os indivíduos não-brancos, com baixos níveis de escolaridade e residentes na região Nordeste. Outros grupos também mais sujeitos à pobreza crônica identificados pelo modelo são indivíduos do sexo masculino em relação aos do sexo feminino, e os ocupados no setor informal. Por outro lado, há maior incidência de componente transitório da pobreza entre mulheres, indivíduos em famílias chefiadas por mulheres solteiras e com crianças e em famílias chefiadas por desocupados ou ocupado no setor informal. Portanto, neste trabalho, os grupos inseridos no setor informal são caracterizados tanto por uma elevada privação estrutural quanto por um alto grau de exposição a choques.

A relação entre dinâmica da pobreza e inserção no mercado de trabalho compreende questões como o que direciona certos grupos pobres a escaparem desta condição e o que induz outros grupos a entrarem na pobreza. Particularmente, supondo que o mercado de trabalho cumpre uma função fundamental nos determinantes das forças "centrífugas" e "centrípetas" da privação de renda, questiona-se, por exemplo, qual a dinâmica predominante entre trabalhadores inseridos na informalidade. O objetivo geral deste artigo é analisar a relação entre pobreza e forma de inserção no mercado de trabalho no Brasil metropolitano em 2004. Provavelmente, a principal razão para o pouco investimento neste tema no Brasil é a escassez de bases de dados organizadas no formato de painel. A Pesquisa Mensal de Emprego (PME) que, embora se configure neste formato, traz informações apenas do rendimento de trabalho, não considerando outras rendas como de aposentadorias e pensões, transferências públicas e privadas e remuneração de ativos, importantes para a construção da renda da família e para a definição de seu bem-estar. Além disso, a PME não acompanha uma mesma amostra por um período muito longo de tempo, apenas oito meses, e é limitada no número de outras informações. Apesar dessas limitações, a fonte de dados utilizada são os microdados desta pesquisa, devido suas informações longitudinais de domicílios e sua qualidade na caracterização do mercado de trabalho urbano. Ademais, cerca de $76 \%$ das rendas das famílias provêm dos rendimentos do trabalho, este é, portanto, o principal fator determinante para análises que envolvam bem-estar das famílias, particularmente das mais pobres.

A medida de pobreza adotada para cada indivíduo, neste trabalho, deriva da comparação de sua renda domiciliar equivalente com uma linha de pobreza, definida a partir da distribuição da 
renda agregada. O modelo de mobilidade, ou de transição na pobreza, é baseado em uma matriz de Markov. Nesta matriz, acompanha-se a probabilidade de um indivíduo estar na pobreza no período inicial, assim como a sua probabilidade de transitar para um outro estado no período seguinte. Como estratégia para estimação desta matriz, em termos de regressão, optou-se por utilizar um modelo probit com seleção amostral, sugerido por Van de Ven e Van Pragg (1981).

\section{TRANSIÇÕES NA POBREZA E MERCADO DE TRABALHO: BREVE REVISÃO DA LITE- RATURA}

As transições em níveis de renda inferiores envolvem conceitos de mobilidade e, portanto, de episódios que podem ser definidos como saída e entrada na pobreza, além da permanência na mesma. Os dois primeiros estão associados à noção de pobreza transitória, definida por Jalan e Ravallion $(1998,2000)$ como a perda de bem-estar associada à variabilidade na renda ou consumo, ao passo que a permanência é traduzida em termos da pobreza crônica. Na definição de Hulme e Shepherd (2003), a permanência na pobreza por um período superior a cinco anos pode ser identificada como pobreza crônica. Os autores colocam que quanto mais tempo a pessoa permanece na pobreza, maior é a sua probabilidade de ser pobre durante toda sua vida, podendo ainda transmitir sua condição a gerações subseqüentes, como é o caso apontado por Harper et al. (2003).

Vulnerabilidade é, consensualmente, definida como a perda de bem-estar, sob normas socialmente aceitas, causada pela incerteza de eventos, associada à ausência de instrumentos apropriados para gerenciá-la (World Bank, 2003). Esses eventos podem ser a perda de um emprego, uma despesa não esperada, uma doença, uma recessão econômica, entre outras coisas. De fato, os pobres são os que mais sofrem com a incerteza sobre eventos futuros, pois são os que possuem os menores recursos, sendo, portanto, os mais vulneráveis (Chaudhuri et al., 2002). No entanto, é possível identificar um grupo de indivíduos não-pobres que, dadas as suas atuais condições, podem ser reconhecidos como altamente vulneráveis à pobreza futura (Dercon, 2001).

Apesar de haver aqueles não-pobres altamente vulneráveis, podem também existir as experiências bem-sucedidas de mobilidade. Vários estudos tratam das formas de escapar da pobreza. Mckay e Lawson (2003) apontam que alguns fatores identificados entre famílias transitoriamente pobres (como a posse de terra, a educação, a migração e o trabalho) estão fortemente associados a transições positivas. A literatura de mobilidade na pobreza chama atenção para o papel que a posse de ativos assume nas transições ou permanência neste estado. Sen (2003), citando Ellis, considera que os ativos podem ser definidos como naturais, humanos, físicos, financeiros e sociopolíticos. Os pobres seriam, portanto, aqueles grupos que são privados destes ativos ou os detêm em escassa quantidade, e esta insuficiência de ativos cria um círculo vicioso da pobreza, uma vez que torna os pobres incapazes de usufruir o crescimento econômico, o que os deixa relativamente mais pobres.

Sen (2003), por sua vez, busca definir os motores que impulsionam a saída da pobreza, comparando as capacitações e as oportunidades de grupos de pobres na área rural de Bangladesh. Ressalta que os motores não são somente exógenos, como impactos de políticas públicas, mas são também endógenos, uma vez que as políticas são universais, mas nem todos usufruem positivamente no sentido de escapar da pobreza. Existem, portanto, características intrínsecas a estes grupos que os tornam mais capazes de realizar a mobilidade ascendente. Nestes grupos, observa-se a habilidade de combinar várias estratégias antipobreza, como rápida acumulação de capital humano e físico, maior participação em atividades ocupacionais não-agrícolas, como também a diversificação de fontes de renda. Como os dados revelam apenas a condição inicial na pobreza e a condição 
pós-saída da pobreza das famílias, Sen sugere que o caráter empreendedor, a ambição, etc., devem explicar, também, esta transição.

Segundo Perry et al. (2006), é de importância particular a habilidade do pobre em usar sua força de trabalho (seu mais abundante ativo) ${ }^{1}$ em trabalhos assalariados, de auto-emprego ou em pequenos negócios, para aumentar sua renda potencial de longo prazo e, com isso, transitar da condição de pobre para não-pobre. Jahan (2005), também interessado em estratégias de saída da pobreza, enfatiza o papel da inserção ocupacional. Segundo este autor, no âmbito macroeconômico, o nível de emprego gerado é o principal canal entre crescimento econômico e diminuição da pobreza. Mas para que tal associação venha a ser virtuosa, no sentido da diminuição da pobreza, é necessário que o crescimento econômico se faça por meio de métodos intensivos em trabalho e os benefícios sejam amplamente distribuídos.

O emprego ou a auto-ocupação, ao possibilitar a geração de renda, estimula a reversão do status de pobreza e, ao mesmo tempo, ao se ampliar em larga escala nas atividades intensivas em trabalho, contribui para reduzir a desigualdade da distribuição de rendimentos. Certamente, neste caso, a ocupação no setor informal é um elemento crítico. De um lado, pelas suas características de incorporar atividades que não requerem qualificação da mão-de-obra e outras barreiras à entrada, constitui-se em uma alternativa para aumentar o nível de renda de famílias pobres, não só do trabalhador de referência, mas também de outros membros da família que o ajudem. Por outro lado, tendem a ser atividades econômicas de baixa produtividade, decorrente, sobretudo, do pouco emprego de capital humano ou de inovações tecnológicas.

Entretanto, como bem ressalta Abramovay et al (2003), o setor informal deve ser considerado, também pelas condições que reúne e que o torna um elemento mitigador da pobreza, quais sejam, a perenidade dos negócios, os vínculos de proximidade em que se apóiam e as funções sociais que preenchem. Nesta mesma linha de raciocínio, Perry et al (2006) questionam a visão convencional sobre a inferioridade das atividades do setor informal. Grupos demográficos como jovens, mulheres casadas e trabalhadores não-qualificados podem, diante das condicionantes sociais que enfrentam, preferir o setor, porque conseguem assegurar benefícios não-monetários, tais como maior flexibilidade de jornada de trabalho, exploração de habilidades empresariais e menor regulação.

\section{MOdElo DE MOBILIDAdE NA POBREZA}

Com interesse em analisar a mobilidade na pobreza e seus determinantes por meio do mercado de trabalho, o modelo de análise empírica consiste em uma matriz de Markov de transição de estados entre dois períodos. Este modelo caracteriza-se pela possibilidade de se estimar taxas de permanência e de transição de estados, além de outras medidas de mobilidade. No entanto, segundo Boskin e Nold (1975), algumas suposições são implicitamente assumidas: (i) as probabilidades de transição não dependem do tempo de duração de cada estado; (ii) as probabilidades de transição não dependem dos estados anteriores ao período prévio da matriz; (iii) o tempo é discreto, e (iv) somente um movimento pode ocorrer por unidade de tempo.

Para a estimação dos determinantes de uma matriz de transição entre dois períodos, $t-1$ e $t$, Cappellari e Jenkins (2002a e 2002b) sugerem modelos de probabilidade multivariada, definindo endogenamente as condições iniciais e de transição dos indivíduos. No caso específico deste trabalho, são estimadas simultaneamente a determinação do status de pobreza no período $t-1$ (problema de condição inicial), a determinação do status de pobreza no período $t$ e a correlação entre efeitos

1 Grifo dos autores. 
não-observáveis, afetando esses processos. A combinação desses três componentes caracteriza os determinantes das taxas de persistência na pobreza, em contraponto à saída, e de entrada na pobreza, em contraponto à permanência fora.

Seguindo o modelo de transição proposto por Cappellari e Jenkins (2002a), em $t$-1, pode ser assumido que o indivíduo $i$ é caracterizado pela propensão à pobreza latente $p_{i t-1}^{*}$ na forma:

$$
p_{i t-1}^{*}=z_{i t-1}^{\prime} \beta+\mu_{j}+\xi_{j d-1}
$$

onde $z_{i t-1}$ é um vetor de variáveis explicativas que descrevem o indivíduo $i$ no período $t-1, \beta$ é um vetor de parâmetros, e o termo de erro $u_{j l-1}$ é a soma de um efeito específico de cada indivíduo com um ruído branco ortogonal, $u_{j d-1}=\mu_{j}+\xi_{j d-1}$, que segue uma distribuição normal com média zero.

Um outro componente do modelo é a especificação para o status de pobreza no período $t$, condicionado à pobreza em $t-1$. A função de propensão latente à pobreza $p_{i t}^{*}$ pode ser separada em duas, caracterizando uma função de permanência na pobreza e uma função de transição para este estado da seguinte forma:

$$
\begin{array}{ll}
p_{i t}^{*}=x_{i t-1}^{\prime} \gamma_{1}+\tau_{1 i}+\zeta_{1 i t} & \text { se } p_{i t-1}^{*}>0 \\
p_{i t}^{*}=x_{i t-1}^{\prime} \gamma_{2}+\tau_{2 i}+\zeta_{2 i t} & \text { se } p_{i t-1}^{*} \leq 0
\end{array}
$$

onde $\gamma_{1}$ é o vetor de coeficientes determinantes da permanência na pobreza e $\gamma_{2}$ é o vetor de coeficientes determinantes da transição para a pobreza, $x_{i t-1}$ é o vetor de características individuais e os termos de erro $\varepsilon_{1 i t}$ e $\varepsilon_{2 i t}$ são a soma de um efeito específico, $\tau_{1 i}$ e $\tau_{2 i}$, com um ruído branco ortogonal, $\zeta_{1 i t}$ e $\zeta_{2 i t}$, seguindo distribuições normais com esperança igual a zero. O vetor de características individuais, $x_{i t-1}$, é definido em $t-1$ para evitar qualquer endogeneidade na mudanças de características no momento da transição.

Desde que a equação (2) se refira ao status de pobreza condicionada à pobreza defasada, os termos de erro nessa equação estão correlacionados ao termo de erro na expressão (1) para o status de pobreza incondicional. De acordo com Maddala (1983), é assumido que as distribuições conjuntas dos termos de erro das duas equações são normais bivariadas e caracterizadas por uma correlação estimável. Dado tais suposições, essas correlações são descritas na forma:

$$
\rho_{1} \equiv \operatorname{corr}\left(u_{i t-1}, \varepsilon_{1 i t}\right)=\operatorname{cov}\left(\mu_{i}, \tau_{1 i}\right)
$$

e

$$
\rho_{2} \equiv \operatorname{corr}\left(u_{i t-1}, \varepsilon_{2 i t}\right)=\operatorname{cov}\left(\mu_{i}, \tau_{2 i}\right)
$$

Assim, a distribuição de heterogeneidade não-observada é parametrizada (além das normalizações necessárias) por intermédio de uma correlação cross-section. Os parâmetros $\rho$ 's sumarizam a associação entre fatores específicos não-observáveis, determinando o status de pobreza do período base e a transição da pobreza. Um sinal positivo (ou negativo) indica que uma maior propensão à pobreza no período subseqüente está entre aqueles agentes que eram mais (ou menos) propensos à pobreza inicial. Se $\rho_{1}=\rho_{2}=0$, então não há o problema de condição inicial no modelo: o status de pobreza em $t-1$ seria tratado como exógeno e as equações de entrada e saída da pobreza seriam estimadas usando modelos univariados. Ou seja, supondo a existência, ou não-existência, de uma 
correlação entre os dois distúrbios estruturais, a separação na expressão (2) pode ser dada de forma endógena ou exógena.

Importante salientar que, na presença de duas variáveis endógenas, ou seja, com $\rho_{1}$ ou $\rho_{2} \neq 0$, ocorre um problema na identificação no modelo de acordo com a utilização das variáveis exógenas. Para que não ocorra problemas na identificação, algumas dessas variáveis que afetam a pobreza inicial devem estar condicionadas a não ter efeito sobre a transição, ou seja, devem haver variáveis pertencentes ao vetor $z_{i t-1}$ que não estejam contidas no vetor $x_{i t-1}$, as chamadas variáveis instrumentais.

O interesse particular sobre esse modelo são as probabilidades de transição. A taxa ou probabilidade de permanência na pobreza em $t$, dado $P_{i t-1}$, pode ser representada por:

$$
s_{i t}=\operatorname{Pr}\left(P_{i t}=1 \mid P_{i t-1}=1\right)=\frac{\Phi_{2}\left(x_{i t-1}^{\prime} \gamma_{1}, z_{i t-1}^{\prime} \beta ; \rho_{1}\right)}{\Phi\left(z_{i t-1}^{\prime} \beta\right)}
$$

e a taxa de transição em $t$, dado $\left(1-P_{i t-1}\right)$, pode ser representada por:

$$
e_{i t}=\operatorname{Pr}\left(P_{i t}=1 \mid P_{i t-1}=0\right)=\frac{\Phi_{2}\left(x_{i t-1}^{\prime} \gamma_{2},-z_{i t-1}^{\prime} \beta ;-\rho_{2}\right)}{\Phi\left(-z_{i t-1}^{\prime} \beta\right)}
$$

onde $\Phi($.$) e \Phi_{2}($.$) são as funções de densidade acumulada das distribuições normais univariada e$ bivariada.

Com as taxas de transições estimadas, ou mesmo observadas em uma matriz de Markov, é possível calcular a dependência de estado da cada indivíduo, tida como um indicador de mobilidade. Esse indicador expõe o quanto da pobreza se mantém no período seguinte em decorrência da própria condição inicial. Para os dados observados, identifica-se a Dependência de Estado Agregada (ASD) por meio da diferença entre a probabilidade de ser pobre para aqueles que estavam na pobreza anteriormente e a probabilidade de ser pobre para aqueles que não estavam nessa situação:

$$
\mathrm{ASD}=\left(\frac{\sum_{i \in\left\{P_{i t-1}=1\right\}} \operatorname{Pr}\left(P_{i t}=1 \mid P_{i t-1}=1\right)}{\sum_{i} P_{i t-1}}\right)-\left(\frac{\sum_{i \in\left\{P_{i t-1}=0\right\}} \operatorname{Pr}\left(P_{i t}=1 \mid P_{i t-1}=0\right)}{\sum_{i}\left(1-P_{i t-1}\right)}\right)
$$

Cappellari e Jenkins (2002b) e Arulampalam et al. (2000) apontam que essa medida observada não controla a heterogeneidade entre indivíduos. Para haver este controle sobre a heterogeneidade (observada e não-observada), os autores utilizam uma medida de Dependência de Estado Genuína2 (GSD), definida como a diferença calculada para cada indivíduo entre as taxas (5) e (6). A GSD é estimada, por fim, pelo valor médio dessas diferenças:

$$
\mathrm{GSD}=\left(\frac{1}{I}\right) \sum_{i=1}^{I} \operatorname{Pr}\left(P_{i t}=1 \mid P_{t-1}=1\right)-\operatorname{Pr}\left(P_{t}=1 \mid P_{t-1}=0\right)
$$

onde $I$ é o número total de indivíduos.

2 Também chamada de Dependência de Estado Verdadeira (TSD) por Heckman (1978). 
Independente do conjunto de características dos indivíduos, que contribuem para sua permanência na pobreza, a GSD é tida como um estimador que mensura o processo no qual a pura e simples experiência na pobreza, em um período específico do tempo, torna o indivíduo mais propenso à pobreza em períodos subseqüentes. Portanto, a diferença entre a ASD e a GSD fornece a contribuição das características individuais para a permanência na pobreza (Giraldo et al., 2002).

Contudo, só é possível calcular a GSD a partir da estimação das equações (1)-(4) e das taxas (5) e (6). Como estratégia para esta estimação, optou-se por utilizar um modelo probit com seleção amostral, sugerido por Van de Ven e Van Pragg (1981). A seleção amostral trata, na realidade, de o indivíduo ser ou não pobre no período inicial. Assim, dado que o indivíduo era pobre, estima-se a sua probabilidade de permanência na pobreza. Caso contrário, se a pessoa não era pobre, estima-se sua probabilidade de transitar para a pobreza.

\section{DESCRIÇÃO DA FONTE DE DADOS, TRATAMENTO E ANÁliSE DESCRITIVA DAS VARIÁVEIS}

\subsection{Fonte de dados e tratamento das variáveis}

A base de dados utilizada neste trabalho é a Pesquisa Mensal de Emprego (PME), realizada no ano de 2004 pelo Instituto Brasileiro de Geografia e Estatística (IBGE) em seis regiões metropolitanas do Brasil, a saber: São Paulo, Rio de Janeiro, Belo Horizonte, Porto Alegre, Recife e Salvador. A escolha da mesma justifica-se por permitir o acompanhamento de determinado domicílio, seguindo um esquema de rotação de painéis, em que a amostra mensal é subdividida em oito grupos de rotação e, a cada mês, $25 \%$ da amostra de domicílios é substituída, o que possibilita a investigação de cada domicílio selecionado por quatro meses consecutivos e, após um intervalo de oito meses, por mais quatro meses, quando este é definitivamente excluído da amostra. Desta forma, em qualquer mês, há unidades domiciliares sendo entrevistadas desde a primeira até a oitava vez.

Por meio dos microdados da PME, identificam-se os indivíduos pesquisados por quatro meses consecutivos a partir do confronto do código de cada domicílio, do número de identificação do morador, do sexo, da data de nascimento e da escolaridade do mesmo, divididos, portanto, em 9 ondas. Em razão deste formato de banco de dados e por se estar investigando as transições do primeiro para o segundo mês de entrevista, ${ }^{3}$ os meses da pesquisa, em 2004, incluídos na amostra são de janeiro a outubro. Consideram-se ainda os indivíduos classificados como empregado doméstico e parente do empregado doméstico como pertencentes a outro domicílio, uma vez que a participação de ambos na unidade domiciliar em que estão empregados é unilateral, ou seja, não são provedores de renda, mas apenas consumidores. Além disso, para este trabalho, limitou-se a amostra aos indivíduos com idade entre 18 e 60 anos pelo fato deste intervalo etário envolver indivíduos em idade ativa, evitando possíveis problemas de viés de seleção por se incluir pessoas muito jovens ou muito idosas na amostra. Considerando que há uma atrição na amostra de aproximadamente $25 \%$, e em torno de $2 \%$ possuem informações não respondidas, restam 268.586 indivíduos da amostra potencial de 371.520 indivíduos.

\footnotetext{
São selecionadas para a análise as duas entrevistas consecutivas, dado que, em meses consecutivos, $75 \%$ da amostra se repete. A distribuição da atrição é praticamente uniforme entre pobres e não-pobres. Entre diferentes faixas de renda, há uma pequena variação, indicando que os não-pobres apresentam menor chance de não responder em $t$ (aproximadamente 23\%) do que nas outras faixas $(28 \%)$.
} 
Vale ressaltar que o plano amostral da PME inclui aspectos que definem um "plano amostral complexo", 5 assim, a totalidade dos dados obtidos na pesquisa não pode ser tratada como se fosse formada por observações independentes e identicamente distribuídas. Com isso, de acordo com Pessoa e Silva (1998), em alguns casos, dependendo do tipo de estimador requerido, as estimativas são realizadas pelo método de máxima pseudo-verossimilhança. Com esse método, as análises sobre as observações requerem a utilização, além do peso amostral, de identificadores do estrato geográfico e da unidade primária de amostragem para calcular corretamente as estimativas.

No intuito de analisar a importância do mercado de trabalho para as transições entre estados de pobreza de um mês para o outro é considerada a informação de condição de ocupação na semana de referência, conforme segmento do mercado de trabalho, obtida por meio de cruzamento de informações da PME. São criadas quatro categorias: setor informal, que inclui todos os empregados sem carteira de trabalho assinada nos setores privado e público, bem como aqueles na posição de trabalhador por conta própria, excluindo os profissionais liberais, ${ }^{6}$ setor formal, que inclui todos os empregados com carteira de trabalho assinada nos setores privado e público, os profissionais liberais na posição de trabalhador por conta própria e os militares ou empregados pelo regime jurídico único; desempregados e trabalhadores não-remunerados, incluindo os desocupados e os trabalhadores não-remunerados de membro da unidade domiciliar que era conta própria ou empregador, e inativos, ou pessoas não economicamente ativas.

Com o foco nas mudanças de curto prazo no bem-estar de indivíduos e famílias, o trabalho está baseado em indicadores monetários de renda equivalente na definição de pobreza. A renda equivalente é uma transformação da renda total bruta do domicílio, que fornece um indicador individual ponderado de acordo com parâmetros de escala equivalente de cada membro da família. Diferentes definições de escala de equivalência implicam diferentes suposições a respeito das economias de escala e dos custos intradomiciliares (Muellbauer, 1977; Lanjouw e Ravallion, 1995).

Várias correções são feitas para a obtenção da renda domiciliar. Considerou-se como renda total bruta do domicílio a soma dos ganhos efetivamente recebidos no mês de referência de todos os trabalhos dos membros do domicílio, não havendo nenhuma imputação em casos de resposta não declarada. Portanto, se em algum domicílio houver um indivíduo cuja renda é desconhecida, tanto o indivíduo como seu domicílio são retirados da amostra. A escala de equivalência adotada como referência para a análise é a da OECD, onde o primeiro adulto recebe peso 1, aos demais adultos é atribuído peso 0.7 e a cada criança, menor de 16 anos, peso 0.5. Outras escalas utilizadas para verificar a robustez dos resultados são a escala unitária, que gera o comumente utilizado indicador de renda per capita, e a escala da raiz quadrada (ou square root), que supõe custos decrescentes de escala ao elevar o número de membros que compartilham da mesma renda a $1 / 2$. Além de a renda domiciliar bruta ser ponderada por essas escalas, para haver comparação entre meses e regiões distintas, ela foi corrigida temporalmente pelo deflator de rendimentos da PME - INPC, sugerido por Corseuil e Foguel (2002) e, espacialmente, pelo índice de custo de vida metropolitano sugerido por Azzoni et al. (2003).

A partir das rendas equivalentes calculadas para toda a amostra, define-se como pobre aqueles indivíduos com o indicador monetário abaixo do valor de $70 \%$ da renda equivalente mediana da população. Dentro do grupo de pobres, definiram-se como muito pobres aqueles com renda equivalente abaixo de $60 \%$ dessa mediana e, como extremamente pobres, aqueles com renda equi-

5 Segundo Silva et al. (2002), os aspectos que definem um plano amostral complexo são: estratificação das unidades de amostragem, conglomeração, probabilidades desiguais de seleção em um ou mais estágios e ajustes dos pesos amostrais para calibração com totais populacionais conhecidos.

6 Esta exclusão se justifica pelo fato desses trabalhadores não serem tipicamente do setor informal. 
valente abaixo de $50 \%$ da mediana. Os valores desses cortes, ou linhas de pobreza, estão reportados na Tabela A1 do Anexo.

No Brasil, não há uma linha de pobreza oficial. Alguns estudos utilizam meio salário mínimo no papel de linha de pobreza. No entanto, o poder de compra de um salário mínimo em São Paulo é bastante distinto de seu poder de compra em Recife ou Salvador. Com o foco sobre a mobilidade dentro da distribuição de renda, optou-se por adotar linhas de pobreza relativa. Assim, mudanças provindas de variações na renda agregada não são captadas no modelo. A intenção é, portanto, avaliar a mobilidade decorrente de mudanças na distribuição de renda intra e entre regiões metropolitanas. O uso de linhas de pobreza relativa possui ainda duas vantagens: a facilidade de construção e a possibilidade de comparação com outros estudos internacionais.

Dentro de cada domicílio da amostra, os indivíduos são caracterizados de acordo com as seguintes informações: sexo (masculino ou feminino), cor ou raça (branca ou não-branca), idade em anos, escolaridade (medida em faixas de estudo), condição no domicílio (chefe, cônjuge, filho ou outra condição), condição de ocupação (informal, formal, não-remunerado ou inativo), categoria ocupacional do trabalho principal (doméstica, manual, média ou superior), tempo no emprego no trabalho principal (mais de 2 anos, entre 1 e 2 anos ou menos de 1 ano), horas trabalhadas habitualmente no trabalho principal (mais de 44 horas, entre 30 e 44 horas ou menos de 30 horas por semana). O domicílio, formado pelo total de moradores nele residente, é, por sua vez, caracterizado pela região metropolitana de localização, tamanho (medido pelo número de moradores), proporção de crianças (com menos de 16 anos) e idosos (com mais de 60 anos) e presença de famílias conviventes, além de sexo, idade e estado conjugal (casado/em união consensual ou não) da pessoa responsável.

Os anos de estudos dos indivíduos foram categorizados pela PME em 5 faixas de escolaridade: sem escolaridade ( 0 ou menos de 1 ano de estudo completo); escolaridade primária incompleta (entre 1 e 3 anos de estudo completos); escolaridade primária completa (entre 4 e 7 anos de estudo completos); ensino fundamental completo (entre 8 e 10 anos de estudo completos), e ensino médio completo (mais de 11 anos de estudo completos).

Para lidar com o problema relacionado à identificação do modelo, é necessário ainda selecionar alguma variável que determine a condição inicial de pobreza, mas que não tenha efeito sobre a transição. Infelizmente, a PME possui um conjunto não muito amplo de informações, restringindo a possibilidade de captar bons instrumentos. Apesar disso, a opção foi utilizar o status de pobreza no período inicial de acordo com a renda domiciliar habitual, entendida como uma proxy para a renda permanente do domicílio. Ou seja, supôs-se que o chamado status de pobreza habitual está relacionado somente ao fato de as pessoas serem ou não serem pobres efetivamente; a mobilidade, por sua vez, responderia somente ao status de pobreza efetiva.

7 Para fins de análise neste artigo, consideraram-se apenas duas categorias para cor do indivíduo: branca, referente às pessoas de cor branca e amarela, e não-branca, referente aos demais indivíduos.

8 A definição de categorias ocupacionais leva em conta a habilidade, em especial, a escolaridade para definir os grupos ocupacionais. Desta forma, a categoria Manual compreende as ocupações que requerem mais habilidades manuais do que cognitivas. Por outro lado, a categoria Superior engloba as ocupações que exigem mais habilidades cognitivas apreendidas no ensino superior. A categoria Média restringe-se àquelas ocupações de nível técnico, e as de emprego doméstico, embora predominantemente manuais, estão separadas em um grupo à parte, devido a suas particularidades: são quase integralmente femininas, a atividade se faz em residências, entre outras.

9 A renda domiciliar habitual é formada pelo somatório das rendas habitualmente recebidas pelos indivíduos em todos os trabalhos. 


\subsection{ANÁLISE DESCRITIVA DAS VARIÁVEIS}

De acordo com a Tabela A2 do Anexo, da amostra resultante, $42 \%$ residem na região metropolitana de São Paulo e $28 \%$ na região metropolitana do Rio de Janeiro; $54 \%$ são mulheres, $43 \%$ são não-brancos e $40 \%$ são chefes de família. No que tange à escolaridade, $48 \%$ possui o ensino médio completo, seguido de $25 \%$ com ensino primário completo. Observa-se ainda que, em média, os domicílios são formados por $19 \%$ de crianças e $6 \%$ de idosos. O porcentual de famílias que convive com outras famílias na mesma unidade domiciliar é de $6 \%$. Aproximadamente $30 \%$ estão ocupados em atividades manuais, $44 \%$ se encontram há mais de dois anos no emprego e 33\% trabalham habitualmente de 30 a 44 horas semanais. O segmento formal emprega aproximadamente $38 \%$ e o informal $26 \%$. Além disso, $9 \%$ são classificados como desempregados ou trabalhadores sem remuneração e $27 \%$ como inativos.

Ao se analisar separadamente cada uma das condições de ocupação (Tabela A3 do Anexo), observa-se a predominância dos homens nos segmentos formal e informal, respectivamente, $60 \%$ e $51 \%$, ao passo que, entre os desempregados e trabalhadores sem remuneração e inativos, as mulheres se destacam, perfazendo $59 \%$ no primeiro caso e $75 \%$ no segundo. Um fato curioso é a maioria de não-brancos (51\%) apenas entre os desempregados e trabalhadores sem remuneração, provavelmente, combinada à condição no domicílio, pode indicar maior desutilidade do trabalho por parte destes indivíduos. Os cônjuges prevalecem entre os inativos, totalizando 45\%, enquanto os filhos entre os desempregados e trabalhadores sem remuneração, $46 \%$. Como já era de se esperar, existe uma grande diferença no grau de escolaridade dos indivíduos ocupados em cada um dos segmentos. Cerca de $65 \%$ no segmento formal possui ensino médio completo enquanto que, no informal, apenas $36 \%$. No caso de desempregados e inativos, sobressaem os indivíduos com ensino médio completo.

Como reflexo do grau de escolaridade em cada um dos segmentos, nota-se o destaque do trabalho manual no setor informal, 55\% dos indivíduos encontram-se neste tipo de trabalho, seguido de $19 \%$ em atividades técnicas e $16 \%$ em atividades domiciliares. Por outro lado, no setor formal, $41 \%$ estão ocupados em trabalhos manuais, $34 \%$ em atividades técnicas e $25 \%$ como profissionais de nível superior. Quanto ao tempo no emprego, embora em ambos os setores a permanência seja superior a dois anos, verifica-se, no setor formal, apenas $15 \%$ dos ocupados há menos de um ano, perante $26 \%$ no segmento informal. A jornada de trabalho habitual também difere entre os setores, observa-se uma maior flexibilidade no informal: $43 \%$ trabalham de 30 a 44 horas semanais, 36\% mais de 44 horas, $11 \%$ de 20 a 30 horas e $10 \%$ menos de 20 horas. Já no setor formal, apenas $5 \%$ e $2 \%$ trabalham, respectivamente, de 20 a 30 horas e menos de 20 horas semanais.

\section{RESUltados}

\subsection{Matrizes de transição}

As taxas de transição observadas entre o status de pobreza em $t-1$ e em $t$, de acordo com a renda equivalente de escala OECD, renda per capita domiciliar e renda equivalente com escala de raiz quadrada, são, respectivamente, apresentadas na Tabela 1. Na amostra, observa-se que a permanência média é maior nas duas condições extremas: não-pobre e extremamente pobre. No caso da primeira, a taxa média observada oscila entre 95,5\% (pela renda per capita domiciliar) e 96,07\% (pela da OECD). Entre os extremamente pobres, a taxa de permanência observada varia de 85,56\% 
(pela da OECD) e 86,46\% (pela renda per capita domiciliar), mostrando que a renda equivalente de escala OECD é mais sensível aos extratos de renda mais alta e a de renda per capita, por sua vez, à pobreza. A taxa de permanência nas condições pobre e muito pobre fica em torno dos $50 \%$, conforme as várias medidas de renda. É, no entanto, entre estes dois status de pobreza que ocorre maior mobilidade. Segundo a renda equivalente de escala OECD, cerca de $33 \%$ dos pobres em $t$ - 1 migram para a condição não-pobre em $t, 9 \%$ saem do mesmo status em $t-1$ e vão para muito pobre no segundo momento, e algo em torno de $11 \%$ segue para a condição extremamente pobre em $t$. Na condição inicial de muito pobre, $18 \%$ transitam para não-pobre, $13 \%$ para pobre e $19 \%$ para extremamente pobre. Para um período de apenas dois meses, é elevada a taxa de transição observada nestas duas condições e o peso da mobilidade ascendente é maior do que da descendente. Embora ocorra uma tênue diferença entre as taxas para outras medidas de renda, a magnitude e a direção são as mesmas.

Tabela 1 - Matriz de Markov com taxas mensais observadas de permanência e transição na pobreza, definida segundo a renda equivalente de escala OECD, per capita e raiz quadrada

\begin{tabular}{|c|c|c|c|c|c|}
\hline \multirow[b]{2}{*}{ Status de pobreza em $t-1$} & \multicolumn{5}{|c|}{ Status de pobreza em $t$} \\
\hline & não-pobre & pobre & muito pobre & $\begin{array}{l}\text { extremamente } \\
\text { pobre }\end{array}$ & TOTAL \\
\hline \multicolumn{6}{|l|}{ escala OECD } \\
\hline não-pobre & 96.07 & 1.32 & 0.81 & 1.80 & 76.35 \\
\hline pobre & 32.85 & 47.26 & 8.93 & 10.95 & 3.53 \\
\hline muito pobre & 18.18 & 12.90 & 50.44 & 18.77 & 3.36 \\
\hline extremamente pobre & 7.70 & 2.59 & 4.21 & 85.56 & 16.76 \\
\hline TOTAL & 76.53 & 3.52 & 3.34 & 16.61 & 100 \\
\hline \multicolumn{6}{|l|}{ escala per capita } \\
\hline não-pobre & 95.50 & 1.50 & 1.08 & 1.92 & 72.20 \\
\hline pobre & 30.03 & 48.79 & 9.38 & 12.06 & 3.79 \\
\hline muito pobre & 19.28 & 11.08 & 50.84 & 18.80 & 4.24 \\
\hline extremamente pobre & 6.41 & 2.14 & 4.99 & 86.46 & 19.77 \\
\hline TOTAL & 72.37 & 3.80 & 4.22 & 19.61 & 100 \\
\hline \multicolumn{6}{|l|}{ escala raiz quadrada } \\
\hline não-pobre & 95.53 & 1.64 & 0.96 & 1.86 & 72.90 \\
\hline pobre & 31.44 & 49.41 & 8.51 & 10.64 & 4.34 \\
\hline muito pobre & 17.27 & 12.90 & 52.07 & 18.25 & 4.08 \\
\hline extremamente pobre & 6.63 & 2.69 & 4.63 & 86.05 & 18.69 \\
\hline TOTAL & 73.09 & 4.32 & 4.07 & 18.53 & 100 \\
\hline
\end{tabular}

Fonte: elaboração própria a partir da PME 2004.

Controlando pela inserção ocupacional no setor informal em $t-1$, nota-se, pela leitura da segunda coluna na Tabela 2, que a transição mais vantajosa do ponto de vista da melhoria de bem-estar é a saída do informal em $t-1$ para uma ocupação formal em $t$. Tem-se que a taxa de permanência observada na não-pobreza é mais alta $(98,14 \%)$, assim como as transições de pobre para não-pobre $(54,21 \%)$, de muito pobre para não-pobre $(33,95 \%)$ e de extremamente pobre para não-pobre $(27,57 \%)$. Quem permanece na informalidade em t apresenta a segunda melhor situação em termos de permanência e transição para a não-pobreza. Por fim, sair da ocupação (PEA não-remunerada) no segundo momento parece ser a pior situação. Cabe destacar, no entanto, que o porcentual de 
não-pobres que permanecem não-pobres, saindo do setor informal e tornando-se desempregados ou trabalhadores não remunerados, é alto, 63,28\%. Provavelmente, trata-se de jovens de famílias mais ricas que preferem transitar de uma inserção ocupacional no informal para a desocupação, porque contam com outras rendas.

No caso dos ocupados nas condições de pobre e de muito pobre em $t$ - 1 , observa-se que, ao perderem o posto de trabalho em $t$, transitam para estados piores e, em maior intensidade, para a condição extremamente pobre.

Tabela 2 - Matriz de Markov com taxas mensais observadas de permanência e transição na pobreza, definida segundo a renda equivalente com escala $\mathrm{OECD}$, para indivíduos no setor informal em $t-1$

\begin{tabular}{|c|c|c|c|c|c|c|}
\hline \multirow[b]{2}{*}{ Status de pobreza em $t-1$} & \multicolumn{4}{|c|}{ Status de pobreza em $t$} & \multirow[b]{2}{*}{ TOTAL } & \multirow[b]{2}{*}{ ASD } \\
\hline & não-pobre & pobre & muito pobre & $\begin{array}{c}\text { extremamente } \\
\text { pobre }\end{array}$ & & \\
\hline \multicolumn{7}{|c|}{ amostra do setor informal em $t$} \\
\hline não-pobre & 96.38 & 1.47 & 0.94 & 1.20 & 80.15 & \\
\hline pobre & 32.87 & 48.72 & 9.56 & 8.86 & 4.29 & 80.68 \\
\hline muito pobre & 17.49 & 13.68 & 52.24 & 16.82 & 4.46 & 78.98 \\
\hline extremamente pobre & 8.47 & 4.41 & 8.11 & 79.01 & 11.10 & 76.66 \\
\hline TOTAL & 80.37 & 4.37 & 4.39 & 10.87 & 100 & \\
\hline \multicolumn{7}{|c|}{ amostra do setor formal em $t$} \\
\hline não-pobre & 98.14 & 0.87 & 0.51 & 0.47 & 89.35 & \\
\hline pobre & 54.21 & 29.63 & 9.76 & 6.40 & 2.97 & 61.52 \\
\hline muito pobre & 33.95 & 12.55 & 42.44 & 11.44 & 2.71 & 58.42 \\
\hline extremamente pobre & 27.57 & 9.05 & 11.87 & 51.31 & 4.97 & 50.34 \\
\hline TOTAL & 91.59 & 2.45 & 2.49 & 3.47 & 100 & \\
\hline \multicolumn{7}{|c|}{ amostra PEA não-remunerada em $t$} \\
\hline não-pobre & 63.28 & 5.70 & 5.25 & 25.78 & 72.24 & \\
\hline pobre & 11.09 & 6.18 & 7.68 & 75.27 & 4.69 & 57.44 \\
\hline muito pobre & 7.62 & 4.61 & 3.01 & 84.75 & 5.64 & 59.18 \\
\hline extremamente pobre & 3.90 & 0.92 & 2.87 & 92.31 & 17.43 & 59.70 \\
\hline TOTAL & 47.34 & 4.82 & 4.83 & 43.01 & 100 & \\
\hline
\end{tabular}

Fonte: elaboração própria a partir da PME 2004.

Quando se parte da inserção ocupacional, em $t-1$, no setor formal (Tabela 3), constata-se que as taxas de permanência observadas no estado de pobreza são maiores do que as que têm o setor informal como inserção no mercado de trabalho em $t-1 \mathrm{em}$ quase todas as situações. As exceções são: permanecer no setor formal em $t$ e no estado extremamente pobre $(76,02)$; sair do formal para $o$ informal e permanecer não-pobre $(96,75)$; sair do formal para o informal e permanecer muito pobre $(38,20)$; sair do formal para a não-remuneração e permanecer não-pobre $(56,37)$, e sair do formal para a não-remuneração e permanecer extremamente pobre $(90,16)$. 
Tabela 3 - Matriz de Markov com taxas mensais observadas de permanência e transição na pobreza,definida segundo a renda equivalente com escala OECD, para indivíduos no setor formal em $t-1$

\begin{tabular}{|c|c|c|c|c|c|c|}
\hline \multirow[b]{2}{*}{ Status de pobreza em t-1 } & \multicolumn{4}{|c|}{ Status de pobreza em $t$} & \multirow[b]{2}{*}{ TOTAL } & \multirow[b]{2}{*}{ ASD } \\
\hline & não-pobre & pobre & muito pobre & $\begin{array}{l}\text { extremamente } \\
\text { pobre }\end{array}$ & & \\
\hline \multicolumn{7}{|c|}{ amostra do setor formal em $t$} \\
\hline não-pobre & 98.70 & 0.68 & 0.36 & 0.24 & 93.98 & \\
\hline pobre & 32.54 & 54.07 & 9.57 & 4.78 & 2.09 & 78.95 \\
\hline muito pobre & 17.44 & 13.95 & 56.98 & 11.05 & 1.72 & 76.96 \\
\hline extremamente pobre & 9.95 & 4.52 & 9.50 & 76.02 & 2.21 & 75.49 \\
\hline TOTAL & 93.96 & 2.10 & 1.73 & 2.20 & 100 & \\
\hline \multicolumn{7}{|c|}{ amostra do setor informal em $t$} \\
\hline não-pobre & 96.75 & 1.21 & 0.84 & 1.21 & 91.25 & \\
\hline pobre & 39.42 & 34.85 & 7.47 & 18.26 & 2.41 & 73.43 \\
\hline muito pobre & 22.47 & 14.23 & 38.20 & 25.09 & 2.67 & 71.32 \\
\hline extremamente pobre & 13.35 & 4.90 & 11.17 & 70.57 & 3.67 & 68.28 \\
\hline TOTAL & 90.32 & 2.51 & 2.39 & 4.79 & 100 & \\
\hline \multicolumn{7}{|c|}{ amostra PEA não-remunerada em $t$} \\
\hline não-pobre & 56.37 & 4.71 & 3.20 & 35.72 & 88.13 & \\
\hline pobre & 9.95 & 8.96 & 0.00 & 81.09 & 4.02 & 49.72 \\
\hline muito pobre & 5.05 & 3.25 & 12.27 & 80.14 & 2.77 & 51.85 \\
\hline extremamente pobre & 5.31 & 1.97 & 2.56 & 90.16 & 5.08 & 51.22 \\
\hline TOTAL & 50.48 & 4.70 & 3.28 & 41.54 & 100 & \\
\hline
\end{tabular}

Fonte: elaboração própria a partir da PME 2004.

No que se refere às transições ascendentes de estado de pobreza, os valores observados são os esperados com relação ao encontrado para a condição inicial no setor informal (Tabela 2). Se o indivíduo permanece no setor formal em t, as transições médias para estados melhores de pobreza do que na condição inicial (abaixo da diagonal principal) são iguais ou maiores e as acima da diagonal são menores ou iguais. Estes resultados mostram que permanecer no setor formal nos dois períodos pode gerar ganhos de bem-estar para o ocupado.

Por outro lado, a transição para o setor informal em $t$, pode incorrer em redução no bem-estar comparativamente à situação inversa reportada na Tabela 2. Não há nada de excepcional neste achado dado que, no informal, o trabalhador recebe, em média, menos do que no formal, porém há uma exceção a esse comportamento: a taxa de transição de extremamente pobre para pobre do ocupado do formal em $t-1$ que segue para o informal em $t$ é maior (9,05\%) do que a de migrar do formal para o informal (4,9\%, na Tabela 3). Certamente, este é um efeito da pouca relevância da escolaridade na determinação de rendimentos dos que estão no setor informal localizados na base da distribuição de rendimentos. Para estes, que tendem a ser menos escolarizados, as chances de perceberem rendimentos mais elevados no informal é maior do que no formal, onde o nível de escolaridade é um critério de seleção e de definição do rendimento (Pianto e Pianto, 2002).

Em relação à migração para a não-remuneração, na Tabela 3, os resultados são mais polêmicos. As taxas observadas de transição que descrevem melhoria de bem-estar são relativamente menores, com exceção de extremamente pobre para não-pobre $(5,31 \%)$ e de extremamente pobre 
para pobre $(1,97 \%)$. Além disso, todas as taxas de transição, que envolvem perda de bem-estar, são inferiores às obtidas se o setor informal é a condição inicial. Neste último caso, estas taxas menores podem ser atribuídas ao papel do seguro-desemprego e das multas rescisórias na geração de renda para aqueles que saem de ocupação formal, proteção que não é assegurada aos que perdem ocupação no informal.

A não-ocupação definida como não-remuneração (Tabela 4) ou como inatividade (Tabela 5) apresenta uma permanência média elevada no estado extremamente pobre se o indivíduo não vai para ocupação: 93,38\%, para a não-remuneração (Tabela 4); 92,33\%, no caso da inatividade (Tabela 5). Por outro lado, encontrar um posto de trabalho no período $t$, em ambas as situações, reduz a permanência média no pior estado de pobreza quando comparados aos valores análogos obtidos se a condição inicial é de ocupado, independente de ser no formal ou no informal.

Tabela 4 - Matriz de Markov com taxas mensais observadas de permanência e transição na pobreza, definida segundo a renda equivalente com escala OECD, para PEA não-remunerada em $t-1$

\begin{tabular}{|c|c|c|c|c|c|c|}
\hline \multirow[b]{2}{*}{ Status de pobreza em $t-1$} & \multicolumn{4}{|c|}{ Status de pobreza em $t$} & \multirow[b]{2}{*}{ TOTAL } & \multirow[b]{2}{*}{ ASD } \\
\hline & não-pobre & pobre & muito pobre & $\begin{array}{l}\text { extremamente } \\
\text { pobre }\end{array}$ & & \\
\hline \multicolumn{7}{|c|}{ Amostra PEA não-remunerada em $t$} \\
\hline não-pobre & 94.44 & 1.95 & 1.01 & 2.60 & 53.45 & \\
\hline pobre & 27.57 & 55.80 & 7.88 & 8.75 & 4.57 & 88.06 \\
\hline muito pobre & 12.06 & 13.51 & 58.84 & 15.59 & 4.81 & 88.50 \\
\hline extremamente pobre & 3.04 & 1.40 & 2.18 & 93.38 & 37.17 & 89.34 \\
\hline TOTAL & 53.45 & 4.76 & 4.54 & 37.25 & 100 & \\
\hline \multicolumn{7}{|c|}{ Amostra do setor informal em $t$} \\
\hline não-pobre & 97.32 & 1.17 & 0.37 & 1.14 & 46.35 & \\
\hline pobre & 92.18 & 3.27 & 0.73 & 3.64 & 5.50 & 50.93 \\
\hline muito pobre & 67.16 & 9.72 & 10.46 & 12.84 & 5.45 & 46.58 \\
\hline extremamente pobre & 37.80 & 10.56 & 9.67 & 41.92 & 42.70 & 39.42 \\
\hline TOTAL & 69.98 & 5.76 & 4.92 & 19.34 & 100 & \\
\hline \multicolumn{7}{|c|}{ Amostra do setor formal em $t$} \\
\hline não-pobre & 96.67 & 1.32 & 0.52 & 1.50 & 62.13 & \\
\hline pobre & 97.55 & 2.45 & 0.00 & 0.00 & 3.27 & 18.59 \\
\hline muito pobre & 94.61 & 2.36 & 0.00 & 2.69 & 2.97 & 13.93 \\
\hline extremamente pobre & 74.49 & 8.44 & 7.37 & 9.71 & 31.63 & 8.23 \\
\hline TOTAL & 89.62 & 3.65 & 2.65 & 4.08 & 100 & \\
\hline
\end{tabular}

Fonte: elaboração própria a partir da PME 2004.

No que tange às transições de estado observadas na pobreza, tanto em termos de direção como de magnitude, os resultados são consistentes, uma vez que sair da não-ocupação para a ocupação significa transitar de estados de pobreza de pior bem-estar para de melhor ${ }^{10} \mathrm{em}$ uma proporção maior (Tabela 4 e 5) do que as verificadas quando o indivíduo sai da ocupação para a não-ocupação (conforme o reportado nas Tabela 2 e 3), e o contrário, ou seja, proporções menores se a transição é de estado de maior bem-estar para menor bem-estar.

10 Células da matriz abaixo da diagonal principal. 
Ao contrário das tabelas anteriores, que só investigam a transições ocorridas entre a População Economicamente Ativa (PEA), a Tabela 5 analisa o comportamento dos inativos. A razão para isso é que a inatividade inclui o desemprego por desalento, o que é, sem dúvida, um dos principais componentes da pobreza permanente.

Tabela 5 - Matriz de Markov com taxas mensais observadas de permanência e transição na pobreza, definida segundo a renda equivalente com escala OECD, para pessoas inativas em $t-1$

\begin{tabular}{|c|c|c|c|c|c|c|}
\hline \multirow[b]{2}{*}{ Status de pobreza em $t-1$} & \multicolumn{4}{|c|}{ Status de pobreza em $t$} & \multirow[b]{2}{*}{ TOTAL } & \multirow[b]{2}{*}{ ASD } \\
\hline & não-pobre & pobre & muito pobre & $\begin{array}{l}\text { extremamente } \\
\text { pobre }\end{array}$ & & \\
\hline \multicolumn{7}{|l|}{ Amostra de inativos em $t$} \\
\hline não-pobre & 94.72 & 1.81 & 1.05 & 2.42 & 56.96 & \\
\hline pobre & 28.33 & 52.38 & 8.57 & 10.71 & 4.20 & 87.65 \\
\hline muito pobre & 13.82 & 12.41 & 54.80 & 19.20 & 4.27 & 88.00 \\
\hline extremamente pobre & 3.67 & 1.48 & 2.52 & 92.33 & 34.57 & 88.28 \\
\hline TOTAL & 57.00 & 4.27 & 4.17 & 34.56 & 100 & \\
\hline \multicolumn{7}{|c|}{ Amostra do setor informal em $t$} \\
\hline não-pobre & 96.08 & 1.26 & 0.69 & 1.97 & 49.25 & \\
\hline pobre & 77.87 & 6.24 & 5.84 & 10.06 & 4.97 & 50.44 \\
\hline muito pobre & 79.25 & 6.08 & 7.55 & 7.13 & 4.77 & 46.03 \\
\hline extremamente pobre & 37.86 & 8.17 & 11.17 & 42.83 & 41.02 & 39.76 \\
\hline TOTAL & 70.49 & 4.56 & 5.57 & 19.38 & 100 & \\
\hline \multicolumn{7}{|c|}{ Amostra do setor formal em $t$} \\
\hline não-pobre & 98.41 & 0.80 & 0.38 & 0.40 & 57.74 & \\
\hline pobre & 88.37 & 6.72 & 0.00 & 4.91 & 3.87 & 17.73 \\
\hline muito pobre & 90.81 & 2.21 & 5.15 & 1.84 & 2.72 & 13.65 \\
\hline extremamente pobre & 79.09 & 5.63 & 4.96 & 10.32 & 35.67 & 9.59 \\
\hline TOTAL & 90.92 & 2.80 & 2.14 & 4.15 & 100 & \\
\hline
\end{tabular}

Fonte: elaboração própria a partir da PME 2004.

A Dependência de Estado Agregada (ASD), que é medida pela diferença entre a proporção de pobres que estavam na pobreza anteriormente e a proporção de pobres que não estavam nessa situação, a ASD para os que migram para o setor formal é menor em todos os estados analisados em comparação às outras inserções ocupacionais em $t$. Se, por outro lado, o indivíduo permanece no setor formal, a dependência de estado observada é maior em relação àqueles que mudam sua condição de ocupação. Entre aqueles que eram não-remunerados e inativos, a dependência de estado observada é relativamente baixa, variando de $39 \%$ a $51 \%$, quando o indivíduo assume um posto de trabalho no setor informal. Contudo, se o indivíduo transita do setor formal para o informal, a dependência de estado média aumenta para $68 \%$ a $73 \%$. Cabe salientar que a análise da ASD não envolve o controle da heterogeneidade entre os indivíduos, não distinguindo os efeitos da condição inicial dos efeitos das características determinantes da mobilidade. 


\subsection{Efeitos marginais e preditos}

Pelas regressões estimadas do modelo de Markov, constata-se, por meio da significância dos parâmetros $\rho$, que a condição inicial é endógena no processo de transição na pobreza. Portanto, ignorar a endogeneidade da condição inicial pode incorrer em viés dos estimadores de interesse. $\mathrm{O}$ sinal negativo do parâmetro $\rho$ indica que, depois de controlar as características observadas, os indivíduos com maior probabilidade de serem pobres no período inicial são menos propensos à pobreza no período seguinte. Ou seja, um choque não controlado que leva as pessoas à pobreza em um período reduz a probabilidade de permanecer na pobreza no período seguinte. Por outro lado, um choque não-controlado, que retira as pessoas da pobreza em um período, aumenta a probabilidade de transitar para a pobreza no período seguinte.

A Tabela 6 reporta os efeitos marginais estimados para este modelo, enquanto as regressões para condição inicial estão na Tabela A4 do Anexo. Um efeito marginal positivo para a taxa de permanência $(s)$ significa que a pessoa que era pobre possui uma maior probabilidade de permanecer neste estado e um valor negativo indica uma maior probabilidade de transição para fora da pobreza. No que se refere à taxa de transição (e), efeitos marginais positivos implicam uma maior probabilidade de transição para dentro da pobreza, enquanto efeitos negativos representam uma maior probabilidade de permanência na não-pobreza.

Os resultados evidenciam que a informalidade em $t-1$, em relação à não-remuneração e à inatividade, apresenta um efeito ambíguo. A diferença entre informais e não-ocupados é de -7,5\% a $-2,6 \%$ na probabilidade de permanência para a pobreza, enquanto a mesma diferença na probabilidade de transição varia entre $1,2 \%$ a $2,1 \%$. Isto é, a condição inicial de ocupado no setor informal contribui para que os pobres melhorem a sua situação ao mesmo tempo em que essa mesma condição inicial contribui para a transição dos não-pobres. No caso da ocupação inicial no setor formal, o efeito estimado sobre a permanência na pobreza é o esperado, pois é inferior aos das demais condições. No entanto, o trabalho formal pouco se diferencia da condição de não-ocupação quanto ao efeito sobre a taxa de transição para a pobreza.

Em relação à categoria ocupacional, apenas os efeitos estimados sobre a taxa de transição são significativos. De fato, diferenças nessas categorias pouco interferem na mobilidade para fora da pobreza, em contraponto à permanência. Entretanto, em relação à categoria manual, todas as demais reduzem a probabilidade de transição para um estado de privação. A categoria ocupacional de doméstica inclusive possui um efeito menor sobre essa transição do que a categoria média, no corte de renda mais baixo. Efeito semelhante ao da categoria ocupacional é o da jornada de trabalho, que interfere significativamente na probabilidade de transição e não na de permanência.

As diferenças no tempo de ocupação entre os trabalhadores só são significativas sobre a probabilidade de permanecer na pobreza no limite de dois anos. Ou seja, aqueles trabalhadores com mais de dois anos de ocupação detêm maiores chances de sair da pobreza no mês seguinte. Além disso, quanto maior o tempo de ocupação a partir de 1 ano, menor é a probabilidade da pessoa piorar sua condição.

Os domicílios chefiados por mulheres tendem a ser os mais vulneráveis, independente de sua condição inicial (pobreza ou não-pobreza), porque seus efeitos sobre a transição e a permanência são positivos. Por outro lado, os domicílios onde os chefes são casados são aqueles em que os membros possuem maior probabilidade de melhorar sua condição, mantendo-se fora da pobreza. 
Tabela 6 - Efeitos marginais estimados sobre a taxa de persistência e sobre a taxa de transição para a pobreza com o modelo probit com seleção

\begin{tabular}{|c|c|c|c|c|c|c|}
\hline \multirow[b]{2}{*}{ Efeito marginal } & \multicolumn{2}{|c|}{$\mathrm{LP}=50 \%$ mediana } & \multicolumn{2}{|c|}{ LP $=60 \%$ mediana } & \multicolumn{2}{|c|}{ LP $=70 \%$ mediana } \\
\hline & sobre $s$ & sobre e & sobre $s$ & sobre e & sobre $s$ & sobre e \\
\hline \multicolumn{7}{|c|}{$\begin{array}{l}\text { Características individuais } \\
\text { Condição de ocupação }\end{array}$} \\
\hline informal & -0.0745 & 0.0122 & -0.0522 & 0.0162 & -0.0258 & 0.0206 \\
\hline formal & -0.1475 & -0.0070 & -0.1439 & -0.0050 & -0.1043 & -0.0044 \\
\hline \multicolumn{7}{|c|}{ Categoria ocupacional } \\
\hline superior & -0.0788 & -0.0104 & -0.0715 & -0.0149 & -0.1076 & -0.0202 \\
\hline médio & -0.0722 & -0.0074 & -0.0507 & -0.0098 & -0.0406 & -0.0117 \\
\hline doméstica & -0.0081 & -0.0085 & -0.0412 & -0.0069 & -0.0064 & -0.0086 \\
\hline \multicolumn{7}{|l|}{ Tempo de ocupação } \\
\hline entre 1 e 2 anos & -0.0628 & -0.0053 & -0.0581 & -0.0052 & -0.0619 & -0.0072 \\
\hline mais de 2 anos & -0.0773 & -0.0138 & -0.0942 & -0.0169 & -0.1036 & -0.0187 \\
\hline \multicolumn{7}{|l|}{ Jornada de trabalho } \\
\hline entre 30 e 44 horas & -0.0512 & -0.0036 & -0.0385 & -0.0049 & -0.0755 & -0.0061 \\
\hline mais de 44 horas & -0.0524 & -0.0047 & -0.0409 & -0.0062 & -0.0528 & -0.0068 \\
\hline \multicolumn{7}{|c|}{ Características domicílio } \\
\hline chefe mulher & 0.0312 & 0.0040 & 0.0447 & 0.0046 & 0.0287 & 0.0064 \\
\hline chefe casado & -0.0679 & -0.0076 & -0.0462 & -0.0091 & -0.0614 & -0.0077 \\
\hline$\rho$ & -0.3999 & -0.6975 & -0.4017 & -0.6938 & -0.4032 & -0.7230 \\
\hline
\end{tabular}

Fonte: elaboração própria a partir da PME 2004

Nota: as variáveis de controle são sexo, cor, idade do indivíduo e do chefe e seus valores ao quadrado, condição de domicílio, escolaridade, número de membros do domicílio e seu valor ao quadrado, proporção de crianças e de idosos no domicílio, presença de famílias conviventes, regiões de residência e mês de entrevista. Em negrito, estimadores significativos a $1 \%$. $\mathrm{LP}=$ linha de pobreza, $s=$ taxa de permanência, $e=$ taxa de transição.

Número de estratos geográficos = 106; Número de Unidades Primárias de Amostragem = 2065;

Número de observações $=268586$; Tamanho da população $=1.24 \mathrm{e}+08$.

Avaliando os indicadores do modelo, constata-se que, da pobreza em $t$, apenas entre $20 \%$ e 30\% decorre da Dependência de Estado Genuína (GSD), conforme resultados da Tabela 7. Em outras palavras menos de um terço da pobreza é explicado unicamente pelo estado de pobreza no passado, controladas as características individuais observadas e não observadas. Por isso, o restante da dependência de estado, ou da ausência de mobilidade, advém das características individuais. Note que os valores da GSD são, de maneira geral, inferiores aos de ASD observados nas Tabelas 2 a 5 .

O grau de pobreza explicado simplesmente pelo estado de pobreza anterior é maior entre os desocupados, em torno de $30 \%$, principalmente se estas pessoas se mantêm desocupadas no período seguinte. Se o desocupado transita para um emprego formal, o grau de dependência genuína se reduz em três pontos porcentuais; mas se ele transita para a informalidade, a dependência de estado se reduz ainda mais, em torno de sete pontos porcentuais. Por outro lado, se o trabalhador já estava na informalidade, a sua dependência de estado é maior justamente se ele se mantém nesta condição. Portanto, novamente identifica-se o quão ambíguo é o efeito da informalidade sobre a mobilidade em baixa renda.

As taxas de permanência na pobreza $(s)$ são mais altas entre aqueles que estavam desocupados (perto de 60\%), independente da linha utilizada e da posterior condição no mercado de trabalho. 
Além disso, estes desocupados são também os que mais transitam para dentro da pobreza, com uma taxa (e) próxima de $30 \%$. De maneira geral, os pobres com maior probabilidade de saída da pobreza são aqueles que continuam ou transitam para o setor formal.

Tabela 7 - Valores estimados da taxa de persistência (s), da taxa de transição $(e)$ e da Dependência de Estado Genuína (GSD), segundo as condições de ocupação em $t-1$ e $t$.

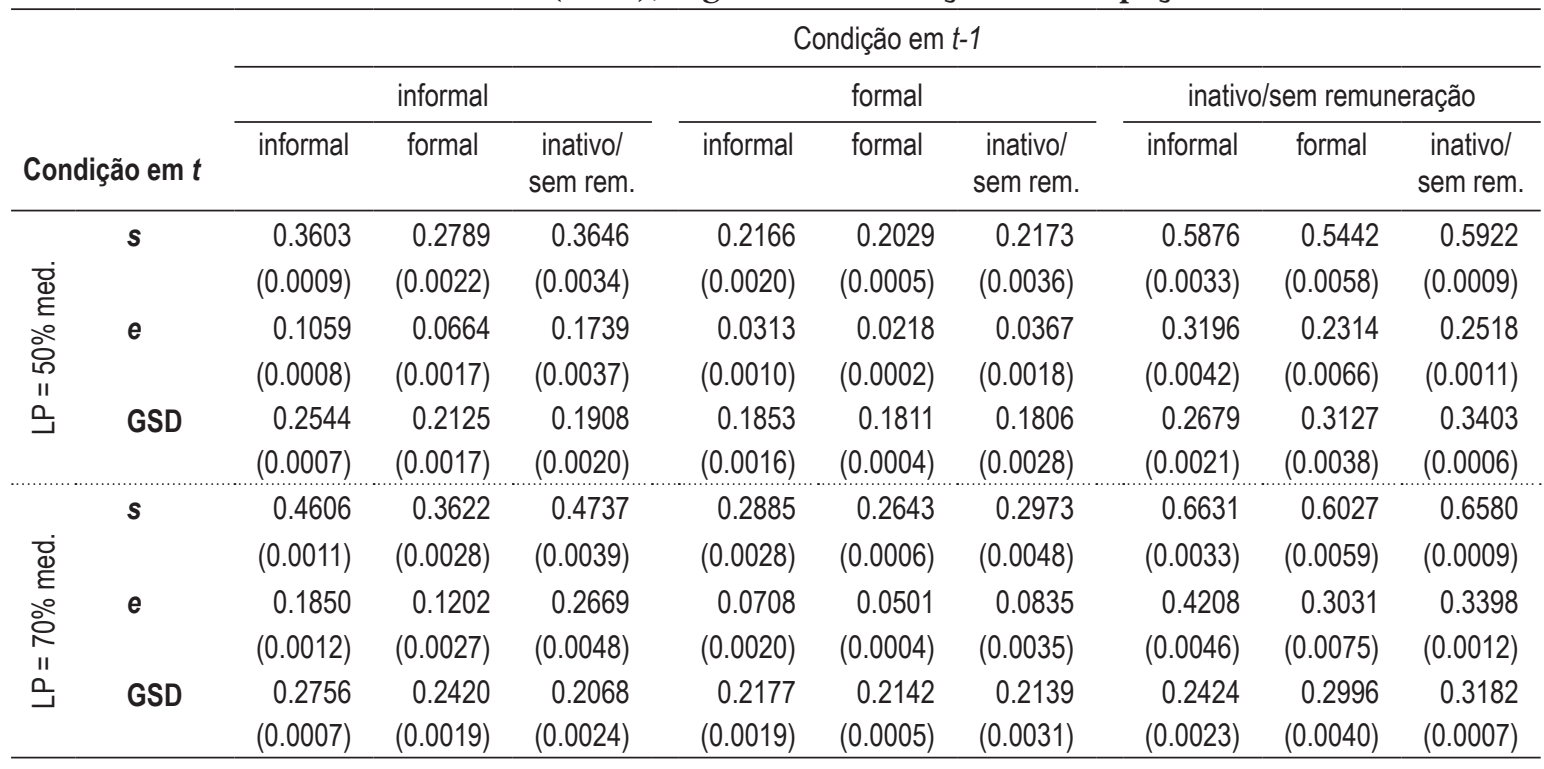

Fonte: elaboração própria a partir da PME 2004.

Nota: $L P=$ linha de pobreza. Número de estratos geográficos $=106$;

Número de Unidades Primárias de Amostragem = 2065;

Número de observações $=268586$; Tamanho da população $=1.24 \mathrm{e}+08$.

\section{CONSIDERAÇÕES FINAIS}

A pergunta subjacente ao objetivo deste artigo é: inserção no mercado de trabalho contribui para melhorar o bem-estar do indivíduo? Por meio da estimação de matrizes de Markov, utilizando um modelo probit com seleção amostral, no qual os determinantes das transições estão relacionados às características do indivíduo, do mercado de trabalho e do domicílio, a resposta é afirmativa. A atividade produtiva remunerada contribui para escapar do estado de privação e para permanecer na não-pobreza.

Obviamente, a melhor condição na ocupação é no setor formal e as transições que se fazem para este setor, mas há uma exceção que merece destaque. Se o indivíduo é extremamente pobre e transita para o estado pobre, é melhor sair do setor formal e ir para o setor informal do que a transição inversa. Esta é mais uma evidência do efeito de características não observadas que permeiam a escolha ocupacional entre aqueles que estão na base da distribuição de rendimentos.

Ainda neste mesmo contexto, inclui-se o resultado observado para a categoria ocupacional de doméstica, que apresenta um efeito menor sobre a transição para a pobreza do que a categoria média, no corte de renda mais baixo. Como as domésticas, nas áreas metropolitanas, percebem rendimentos próximos ao salário mínimo, dificilmente elas transitam para a pobreza, considerando a linha referente a $50 \%$ da mediana. 
De outra forma, a não-ocupação apresenta taxas de permanência muito altas no estado extremamente pobre e, quando o indivíduo migra da não-ocupação para a ocupação, ele melhora seu bem-estar, porque passa para um estado de menor nível de pobreza.

Uma outra evidência que responde afirmativamente à pergunta formulada é a dimensão da GSD. Pouco se pode atribuir à condição inicial do indivíduo e muito às suas características, pessoais, de domicílio e de trabalho. No caso das referentes ao posto de trabalho, nota-se o papel positivo da condição e do tempo de permanência na ocupação.

Em termos de formulação de políticas públicas, sugere-se que, a exemplo de Hulme e Shepherd (2003), para facilitar o acesso à ocupação, no caso de taxas de permanência elevada ou se há maior probabilidade de saída da pobreza, as estratégias devem estar voltadas para medidas que auxiliem os pobres a retomar seu status de não-pobre o mais rápido possível. Nessa linha, programas tais como de requalificação da mão-de-obra, seguro-desemprego, microcrédito, incentivo à pequena unidade de produção, entre outros, podem ser bem-sucedidos.

Além disso, o peso das características individuais como determinantes do estado dependência, mais do que a condição inicial adversa implica que as políticas para suavizar choques no mercado de trabalho, como o seguro-desemprego, devem ser condicionadas à requalificação de mão-deobra, para melhorar o perfil do trabalhador e, com isso, proporcionar condições de evitar a entrada na pobreza. Quanto às políticas de microcrédito e de incentivo à pequena unidade de produção, a intenção é dotar o ocupado no setor informal de recursos que o mantenham fora da pobreza, dado que esse setor é muito mais vulnerável a choques do que o formal.

\section{REFERÊNCIAS BIBLIOGRÁFICAS}

Abramovay, R; Saes, S; Souza, M. C; Magalhães, R. Mercados do empreendedorismo de pequeno porte no Brasil. In: Pobreza e mercados no Brasil, uma análise de iniciativas de políticas públicas. Brasília: Department for International Development/ CEPAL, Escritório no Brasil, 2003.

Arulampalam, W.; Booth, A. L.; Taylor, M. P. Unemployment persistence. Oxford Economic Papers, v. 52, n. 1, p. 24-50, 2000.

Azzoni, C. R.; Menezes, T.; Carmo, H. E. Comparações da paridade do poder de compra entre cidades: aspectos metodológicos e aplicação ao caso brasileiro. Pesquisa e Planejamento Econômico, Rio de Janeiro, v. 33, n. 1, 2003.

Boskin, M. J.; Nold, F. C. A. Markov model of turnover in aid to families with dependent children. Journal of Human Resources, v. 10, n. 4, p. 467-481, 1975.

Camargo, J. M.; Neri, M. C.; Gonzaga, G. Salário mínimo, efeito farol e pobreza. Revista de Economia Política, v. 21, n. 2-82, 2001.

Cappellari, L.; Jenkins, S. P. Modelling low income transitions. Colchester: ISER, 2002a. (Working Paper, 2002-8)

. Who stays poor? Who becomes poor? Evidence from the british household panel survey. The Economic Journal, v. 112, p. C60-C67, Mar. 2002b.

Chaudhuri, S; Jalan, J; Suryahadi, A. Assessing household vulnerability to poverty from cross-sectional data: a methodology and estimates from Indonesia. New York: Columbia University - Department of Economics, abril 2002. (Discussion Paper Series, $\mathrm{n}^{\mathrm{o}}$ 0102-52)

Comim, F. V.; Bagolin, I. Aspectos qualitativos da pobreza no Rio Grande do Sul. Revista Ensaios (FEE), Porto Alegre, v. 23, n. especial, p. 467-490, 2002. 
Corseuil, Carlos Henrique; Foguel, Miguel N. Uma sugestão de deflatores para rendas obtidas a partir de algumas pesquisas domiciliares, Rio de Janeiro, 2002. Disponível em: < http://www.ipea.gov.br/pub/ td/2002/td_0897.pdf>. Acesso em 13 jun. 2006.

Dercon, S. Assessing vulnerability to poverty. Centre for the Study of African Economics, University of Oxford, 2001.

Ferreira, Francisco H. G.; Lanjouw, Peter, Neri, Marcelo C. A Robust poverty profile for Brazil using multiple data sources. Revista Brasileira de Economia, Rio de Janeiro, v. 57, n. 2, p. 59-92, 2003.

Ferreira, Francisco H. G.; Leite, P. G.; Litchfield, J. A. The rise and fall of brazilian inequality: 1981-2004. World Bank Policy Research, Mar. 2006. (Working Paper 3867).

Giraldo, A.; Rettore, E.; Trivellato, U. The persistence of poverty: true state dependence or unobserved heterogeneity? Some evidence from the italian survey on household income and wealth. In: International Conference on Panel Data. Berlin. 10th International Conference on Panel Data, July 2002.

Harper, C.; Marcus, R.; Moore, K. Enduring poverty and the conditions of childhood: lifecourse and intergenerational poverty transmissions. World Development, v. 31, n. 3, p. 535-554, Mar. 2003.

Heckman, J. J. Simple statistical models for discrete panel data developed and applied to test the hypothesis of true state dependence against the hypothesis of spurious state dependence. Annals de INSEE, Paris, p. 227-269, 1978.

Henriques, Ricardo. Desigualdade e pobreza no Brasil. Rio de Janeiro: IPEA, 2000.

Hulme, David; Shepherd, Andrew. Conceptualizing chronic poverty. World Development, v. 31, n. 3, p. 403-423, 2003.

Jahan, Selim. Reorienting development: towards and engendered employment strategy. Brasília: United Nations Development Programme - International Poverty Centre, fev. 2005. (Working Paper, n. 5).

Jalan, J; Ravallion, M. Is transient poverty different? Evidence for rural China. Journal of Development Studies, v. 36, n. 6, p. 82-98, 2000.

Lanjouw, P.; Ravallion, M. Poverty and household size. The Economic Journal, v. 105, p. 1415-1434, Nov. 1995.

Maddala, G. Limited dependent and qualitative variables in econometrics. Cambridge: Cambridge University Press, 1983.

Mckay, A.; Lawson, D. Assessing the extent and nature of chronic poverty in low income countries: issues and evidence. World Development, v. 31, n. 3, p. 425-439, 2003.

Muellbauer, J. Testing the Barten model of household composition effects and the cost of children. Economic Journal, v. 87, p. 460-487, 1977.

Pessoa, D. G. C., Silva, P. L. N. Análise de dados amostrais complexos. Rio de Janeiro: IBGE, 1998.

Perry, Guillermo E.; et al. Poverty reduction and growth: virtuous and vicious circles. Washington: The International Bank for Reconstruction and Development / The World Bank, 2006.

Pianto, Maria E. Tannuri; Pianto, Donald M. Informal employment in Brazil - a choice at the top and segmentation at the bottom: a quantile regression approach. Brasília, agosto de 2002. (Texto para discussão $\left.n^{\circ} 236\right)$.

Ramos, L.; Reis, J. G. A. Salário mínimo, distribuição de renda e pobreza no Brasil. Pesquisa e Planejamento Economico, v. 25, n. 1, 1995.

Ribas, R. P.; Machado, A. F; Golgher, A. Flutuações e persistência na pobreza: uma análise de decomposição transitória-crônica In: XXXIII Encontro Nacional de Economistas - ANPEC. Natal. Anais, 2005.

Rocha, S. Pobreza no Brasil: afinal, de que se trata?. Rio de Janeiro: Editora FGV, 2003.

Schwartzman, S. Pobreza, exclusão social e modernidade: uma introdução ao mundo contemporâneo. São Paulo: Augurium Editora, 2004a. . As Causas da pobreza. Rio de Janeiro: Editora FGV, 2004b. 
Sen, B. Drivers of escape and descent: changing household fortunes in rural Bangladesh. World Development, v. 31, n. 3, p. 513-534, 2003.

Silva, P. L. N., Pessoa, D. G. C., Lila, M. F. Análise estatística de dados da PNAD: incorporando a estrutura do plano amostral. Ciência \& Saúde Coletiva, v. 7, n. 4, p. 659-670, 2002.

World Bank, Inequality in Latin America and the Caribbean - Breaking with History? 2003.

Van de Ven, W., Van Pragg, B. The demand for deductibles in private health insurance: a probit model with sample selection. Journal of Econometrics, v. 17, p. 229-52, 1981. 


\section{ANEXO}

Tabela A1 - Valor das linhas de pobreza em 2004 calculadas a preços de junho de 2006 (R\$) com base na distribuição da renda per capita

\begin{tabular}{lr}
\hline com base na distribuição da renda per capita & \\
$50 \%$ da mediana & 89.40 \\
$60 \%$ da mediana & 107.28 \\
$70 \%$ da mediana & 125.16 \\
com base na distribuição da renda equivalente raiz quadrada & \\
$50 \%$ da mediana & 171.13 \\
$60 \%$ da mediana & 205.35 \\
$70 \%$ da mediana & 239.58 \\
com base na distribuição da renda equivalente OECD & \\
$50 \%$ da mediana & 105.49 \\
$60 \%$ da mediana & 126.58 \\
$70 \%$ da mediana & 147.68 \\
\hline
\end{tabular}

Fonte: elaboração própria a partir da PME 2004.

Tabela A2 - Descrição das variáveis selecionadas

\begin{tabular}{lrr|lrl}
\hline & Média & $\begin{array}{c}\text { Erro padrão } \\
\text { linearizado }\end{array}$ & & Média & $\begin{array}{c}\text { Erro padrão } \\
\text { linearizado }\end{array}$ \\
\hline $\begin{array}{l}\text { Características individuais } \\
\text { mulher }\end{array}$ & 0.53654 & $(0.00128)$ & Região Metropolitana & Recife & \\
idade & 36.3013 & $(0.04703)$ & Salvador & 0.05594 & $(0.00101)$ \\
não-branco & 0.42892 & $(0.00550)$ & Belo Horizonte & 0.07504 & $(0.00141)$ \\
Condição no domicílio & & & Rio de Janeiro & 0.09644 & $(0.00133)$ \\
chefe & 0.40328 & $(0.00159)$ & São Paulo & 0.27664 & $(0.00349)$ \\
cônjuge & 0.28134 & $(0.00142)$ & Porto Alegre & 0.41814 & $(0.00471)$ \\
filho & 0.26116 & $(0.00226)$ & Renda domiciliar habitual em $t-1^{*}$ & 0.07779 & $(0.00115)$ \\
agregado ou pensionista & 0.05199 & $(0.00092)$ & total & 1484.32 & $(37.2104)$ \\
empregado ou parente de empreg. & 0.00223 & $(0.00020)$ & per capita & 463.77 & $(13.2893)$ \\
Escolaridade & & & equivalente raiz quadrada & 809.26 & $(21.4792)$ \\
sem escolaridade & 0.03105 & $(0.00091)$ & equivalente OECD & 591.59 & $(16.4035)$ \\
primário incompleto & 0.05425 & $(0.00136)$ & Renda domiciliar efetiva em $t-1^{*}$ & & \\
primário completo & 0.25172 & $(0.00345)$ & total & 1508.71 & $(37.4745)$ \\
fundamental completo & 0.17928 & $(0.00211)$ & per capita & 471.63 & $(13.4378)$ \\
ensino médio completo & 0.48370 & $(0.00600)$ & equivalente raiz quadrada & 822.72 & $(21.6653)$ \\
Condição na ocupação em $t-1$ & & & equivalente OECD & 601.55 & $(16.5705)$ \\
informal & 0.26044 & $(0.00199)$ & Renda domiciliar efetiva em $\boldsymbol{t}^{*}$ & & \\
formal & 0.37792 & $(0.00265)$ & total & 1496.37 & $(37.9393)$ \\
ativo sem-remuneração & 0.09001 & $(0.00121)$ & per capita & 466.35 & $(13.4248)$ \\
inativo & 0.27163 & $(0.00190)$ & equivalente raiz quadrada & 814.87 & $(21.7948)$ \\
\hline
\end{tabular}




\begin{tabular}{|c|c|c|c|c|c|}
\hline & Média & $\begin{array}{l}\text { Erro padrão } \\
\text { linearizado }\end{array}$ & & Média & $\begin{array}{l}\text { Erro padrão } \\
\text { linearizado }\end{array}$ \\
\hline Condição na ocupação em $t$ & & & equivalente $\mathrm{OECD}$ & 595.11 & $(16.5890)$ \\
\hline informal & 0.26065 & $(0.00199)$ & Pobreza habitual em $t-1$ & & \\
\hline formal & 0.37859 & $(0.00266)$ & escala per capita & & \\
\hline ativo sem-remuneração & 0.09062 & $(0.00123)$ & LP $=70 \%$ da mediana & 0.27958 & $(0.00372)$ \\
\hline inativo & 0.27014 & $(0.00189)$ & $\mathrm{LP}=60 \%$ da mediana & 0.24179 & $(0.00335)$ \\
\hline Categoria ocupacional & & & LP $=50 \%$ da mediana & 0.19930 & $(0.00277)$ \\
\hline superior & 0.12061 & $(0.00340)$ & escala raiz quadrada & & \\
\hline médio & 0.17898 & $(0.00201)$ & LP $=70 \%$ da mediana & 0.27386 & $(0.00350)$ \\
\hline manual & 0.30091 & $(0.00296)$ & $\mathrm{LP}=60 \%$ da mediana & 0.23017 & $(0.00301)$ \\
\hline doméstica & 0.04189 & $(0.00093)$ & LP $=50 \%$ da mediana & 0.18801 & $(0.00252)$ \\
\hline Tempo de ocupação & & & escala OECD & & \\
\hline menos de 1 mês & 0.00776 & $(0.00023)$ & LP $=70 \%$ da mediana & 0.23828 & $(0.00319)$ \\
\hline de 1 mês a 1 ano & 0.12194 & $(0.00127)$ & LP $=60 \%$ da mediana & 0.20294 & $(0.00279)$ \\
\hline entre 1 e 2 anos & 0.07015 & $(0.00085)$ & LP $=50 \%$ da mediana & 0.16799 & $(0.00235)$ \\
\hline mais de 2 anos & 0.44272 & $(0.00241)$ & Pobreza efetiva em $t-1$ & & \\
\hline Jornada de trabalho & & & escala per capita & & \\
\hline menos de 20 horas & 0.03714 & $(0.00070)$ & LP $=70 \%$ da mediana & 0.27726 & $(0.00369)$ \\
\hline entre 20 e 30 horas & 0.05041 & $(0.00081)$ & LP $=60 \%$ da mediana & 0.23994 & $(0.00333)$ \\
\hline entre 30 e 44 horas & 0.33020 & $(0.00239)$ & LP $=50 \%$ da mediana & 0.19823 & $(0.00277)$ \\
\hline mais de 44 horas & 0.22483 & $(0.00207)$ & escala raiz quadrada & & \\
\hline Características domicílio & & & LP $=70 \%$ da mediana & 0.27117 & $(0.00349)$ \\
\hline número de membros & 3.77841 & $(0.01232)$ & LP $=60 \%$ da mediana & 0.22854 & $(0.00300)$ \\
\hline proporção de crianças & 0.18652 & $(0.00168)$ & LP $=50 \%$ da mediana & 0.18730 & $(0.00251)$ \\
\hline proporção de idosos & 0.05670 & $(0.00085)$ & escala OECD & & \\
\hline famílias conviventes & 0.06034 & $(0.00165)$ & LP $=70 \%$ da mediana & 0.23678 & $(0.00317)$ \\
\hline chefe mulher & 0.28298 & $(0.00298)$ & LP $=60 \%$ da mediana & 0.20200 & $(0.00277)$ \\
\hline idade do chefe & 45.6779 & $(0.09687)$ & $\mathrm{LP}=50 \%$ da mediana & 0.16785 & $(0.00235)$ \\
\hline chefe casado & 0.72462 & $(0.00273)$ & Pobreza efetiva em $t$ & & \\
\hline Mês de entrevista & & & escala per capita & & \\
\hline janeiro & 0.10331 & $(0.00168)$ & $\mathrm{LP}=70 \%$ da mediana & 0.27803 & $(0.00368)$ \\
\hline fevereiro & 0.10370 & $(0.00192)$ & LP $=60 \%$ da mediana & 0.24009 & $(0.00329)$ \\
\hline março & 0.10428 & $(0.00194)$ & LP $=50 \%$ da mediana & 0.19768 & $(0.00277)$ \\
\hline abril & 0.10611 & $(0.00191)$ & escala raiz quadrada & & \\
\hline maio & 0.11104 & $(0.00175)$ & LP $=70 \%$ da mediana & 0.27105 & $(0.00346)$ \\
\hline junho & 0.11359 & $(0.00207)$ & LP $=60 \%$ da mediana & 0.22769 & $(0.00299)$ \\
\hline julho & 0.11779 & $(0.00211)$ & $\mathrm{LP}=50 \%$ da mediana & 0.18686 & $(0.00251)$ \\
\hline agosto & 0.12022 & $(0.00210)$ & escala OECD & & \\
\hline \multirow[t]{3}{*}{ setembro } & 0.11996 & $(0.00188)$ & LP $=70 \%$ da mediana & 0.23647 & $(0.00315)$ \\
\hline & & & LP $=60 \%$ da mediana & 0.20115 & $(0.00276)$ \\
\hline & & & $\mathrm{LP}=50 \%$ da mediana & 0.16760 & $(0.00234)$ \\
\hline
\end{tabular}

1 Células da matriz abaixo da diagonal principal. 
Tabela A3 - Médias das variáveis selecionadas, segundo a condição inicial de ocupação

\begin{tabular}{|c|c|c|c|c|}
\hline & \multicolumn{4}{|c|}{ Condição de ocupação em $t-1$} \\
\hline & informal & formal & ativo sem rem. & inativo \\
\hline \multicolumn{5}{|l|}{ Características individuais } \\
\hline mulher & 0.49095 & 0.39800 & 0.59273 & 0.75440 \\
\hline idade & 36.9779 & 35.8444 & 30.1267 & 38.3343 \\
\hline não-branco & 0.47476 & 0.36491 & 0.50346 & 0.44933 \\
\hline \multicolumn{5}{|l|}{ Condição no domicílio } \\
\hline chefe & 0.46735 & 0.50901 & 0.23398 & 0.25085 \\
\hline cônjuge & 0.24777 & 0.19400 & 0.23432 & 0.45062 \\
\hline filho & 0.22466 & 0.25206 & 0.46246 & 0.24212 \\
\hline agregado ou pensionista & 0.05214 & 0.04469 & 0.06908 & 0.05633 \\
\hline empregado ou parente de empregado & 0.00809 & 0.00024 & 0.00017 & 0.00007 \\
\hline \multicolumn{5}{|l|}{ Escolaridade } \\
\hline sem escolaridade & 0.03574 & 0.01014 & 0.01715 & 0.06026 \\
\hline primário incompleto & 0.07388 & 0.02634 & 0.04558 & 0.07714 \\
\hline primário completo & 0.33426 & 0.16532 & 0.21355 & 0.30542 \\
\hline fundamental completo & 0.19335 & 0.14542 & 0.22259 & 0.19853 \\
\hline ensino médio completo & 0.36277 & 0.65278 & 0.50113 & 0.35865 \\
\hline \multicolumn{5}{|l|}{ Condição na ocupação em $t$} \\
\hline informal & 0.83842 & 0.05811 & 0.08948 & 0.04518 \\
\hline formal & 0.09224 & 0.92096 & 0.02698 & 0.01505 \\
\hline ativo sem-remuneração & 0.02685 & 0.00778 & 0.64608 & 0.08295 \\
\hline inativo & 0.04249 & 0.01315 & 0.23746 & 0.85682 \\
\hline \multicolumn{5}{|l|}{ Categoria ocupacional } \\
\hline superior & 0.09551 & 0.25222 & 0.00458 & \\
\hline médio & 0.19458 & 0.33747 & 0.00850 & \\
\hline manual & 0.54883 & 0.40996 & 0.03369 & \\
\hline doméstica & 0.16084 & & & \\
\hline \multicolumn{5}{|l|}{ Tempo de ocupação } \\
\hline menos de 1 mês & 0.01821 & 0.00786 & 0.00055 & \\
\hline de 1 mês a 1 ano & 0.25426 & 0.14547 & 0.00829 & \\
\hline entre 1 e 2 anos & 0.11441 & 0.10574 & 0.00431 & \\
\hline mais de 2 anos & 0.61313 & 0.74093 & 0.03363 & \\
\hline \multicolumn{5}{|l|}{ Jornada de trabalho } \\
\hline menos de 20 horas & 0.10270 & 0.02534 & 0.00903 & \\
\hline entre 20 e 30 horas & 0.11318 & 0.05322 & 0.00908 & \\
\hline entre 30 e 44 horas & 0.42746 & 0.57583 & 0.01387 & \\
\hline mais de 44 horas & 0.35666 & 0.34561 & 0.01480 & \\
\hline \multicolumn{5}{|l|}{ Características domicílio } \\
\hline número de membros & 3.77298 & 3.61914 & 4.05499 & 3.91357 \\
\hline proporção de crianças & 0.19751 & 0.18148 & 0.18692 & 0.18284 \\
\hline proporção de idosos & 0.04871 & 0.05021 & 0.05873 & 0.07273 \\
\hline famílias conviventes & 0.06356 & 0.04764 & 0.08951 & 0.06525 \\
\hline chefe mulher & 0.30354 & 0.25397 & 0.35416 & 0.28003 \\
\hline idade do chefe & 45.1453 & 44.3742 & 45.9304 & 47.9186 \\
\hline chefe casado & 0.69695 & 0.74426 & 0.67274 & 0.74104 \\
\hline
\end{tabular}




\begin{tabular}{|c|c|c|c|c|}
\hline & \multicolumn{4}{|c|}{ Condição de ocupação em $t$ - 1} \\
\hline & informal & formal & ativo sem rem. & inativo \\
\hline \multicolumn{5}{|l|}{ Mês de entrevista } \\
\hline janeiro & 0.10305 & 0.10104 & 0.10017 & 0.10777 \\
\hline fevereiro & 0.10144 & 0.10180 & 0.10687 & 0.10745 \\
\hline março & 0.10214 & 0.10346 & 0.11416 & 0.10419 \\
\hline abril & 0.10462 & 0.10579 & 0.11867 & 0.10382 \\
\hline maio & 0.11173 & 0.11022 & 0.11704 & 0.10955 \\
\hline junho & 0.11246 & 0.11492 & 0.11125 & 0.11361 \\
\hline julho & 0.11809 & 0.11901 & 0.10957 & 0.11852 \\
\hline agosto & 0.12343 & 0.12138 & 0.11280 & 0.11797 \\
\hline setembro & 0.12304 & 0.12239 & 0.10947 & 0.11712 \\
\hline \multicolumn{5}{|l|}{ Região Metropolitana } \\
\hline Recife & 0.05192 & 0.04241 & 0.06551 & 0.07544 \\
\hline Salvador & 0.07689 & 0.06474 & 0.09906 & 0.07966 \\
\hline Belo Horizonte & 0.09201 & 0.10042 & 0.08279 & 0.09968 \\
\hline Rio de Janeiro & 0.29819 & 0.26276 & 0.22705 & 0.29173 \\
\hline São Paulo & 0.41229 & 0.44167 & 0.46640 & 0.37502 \\
\hline Porto Alegre & 0.06871 & 0.08800 & 0.05918 & 0.07847 \\
\hline \multicolumn{5}{|l|}{ Pobreza habitual em $t-1$} \\
\hline \multicolumn{5}{|l|}{ escala per capita } \\
\hline $\mathrm{LP}=70 \%$ da mediana & 0.24472 & 0.09638 & 0.52307 & 0.48722 \\
\hline $\mathrm{LP}=60 \%$ da mediana & 0.19923 & 0.06898 & 0.47853 & 0.44458 \\
\hline $\mathrm{LP}=50 \%$ da mediana & 0.14677 & 0.04312 & 0.42141 & 0.39338 \\
\hline \multicolumn{5}{|l|}{ escala raiz quadrada } \\
\hline $\mathrm{LP}=70 \%$ da mediana & 0.24792 & 0.09118 & 0.51157 & 0.47412 \\
\hline $\mathrm{LP}=60 \%$ da mediana & 0.19465 & 0.06068 & 0.45523 & 0.42547 \\
\hline $\mathrm{LP}=50 \%$ da mediana & 0.14174 & 0.03563 & 0.40008 & 0.37413 \\
\hline \multicolumn{5}{|l|}{ escala OECD } \\
\hline $\mathrm{LP}=70 \%$ da mediana & 0.19562 & 0.06510 & 0.47603 & 0.44135 \\
\hline $\mathrm{LP}=60 \%$ da mediana & 0.15300 & 0.04332 & 0.42788 & 0.39838 \\
\hline $\mathrm{LP}=50 \%$ da mediana & 0.10911 & 0.02449 & 0.37937 & 0.35406 \\
\hline número de observações & 68998 & 99371 & 24219 & 75998 \\
\hline tamanho da população & $3.20 \mathrm{E}+07$ & $4.70 \mathrm{E}+07$ & $1.10 \mathrm{E}+07$ & $3.40 E+07$ \\
\hline
\end{tabular}

Fonte: elaboração própria a partir da PME 2004.

Nota: * valor das rendas a preços de maio de 2006 Em 2004 LP = linha de pobreza. 
Tabela A4 - Coeficientes estimados para regressão do status inicial de pobreza

\begin{tabular}{|c|c|c|c|}
\hline & $L P=50 \%$ mediana & $\mathrm{LP}=60 \%$ mediana & $\mathrm{LP}=70 \%$ mediana \\
\hline \multicolumn{4}{|l|}{ Características individuais } \\
\hline mulher & -0.1060 & -0.0409 & -0.0540 \\
\hline idade & 0.0024 & -0.0069 & -0.0001 \\
\hline idade ao quadrado & 0.0000 & 0.0001 & 0.0000 \\
\hline não-branco & 0.0789 & 0.0530 & 0.1019 \\
\hline \multicolumn{4}{|l|}{ condição no domicílio } \\
\hline chefe & 0.0597 & 0.0558 & 0.1172 \\
\hline cônjuge & -0.0391 & -0.0909 & -0.0359 \\
\hline filho & 0.0827 & 0.0158 & 0.0972 \\
\hline \multicolumn{4}{|l|}{ escolaridade } \\
\hline sem escolaridade & 0.1012 & 0.1476 & 0.1321 \\
\hline primário incompleto & 0.1831 & 0.2034 & 0.1773 \\
\hline primário completo & 0.1545 & 0.1749 & 0.1654 \\
\hline fundamental completo & 0.1063 & 0.1121 & 0.0946 \\
\hline \multicolumn{4}{|l|}{ condição de ocupação } \\
\hline informal & 0.1647 & 0.1549 & 0.1707 \\
\hline formal & -0.3078 & -0.2784 & -0.1878 \\
\hline \multicolumn{4}{|l|}{ Categoria ocupacional } \\
\hline superior & -0.2197 & -0.3650 & -0.2641 \\
\hline médio & -0.1878 & -0.2045 & -0.1285 \\
\hline doméstica & -0.2189 & -0.2161 & -0.1181 \\
\hline \multicolumn{4}{|l|}{ Tempo de ocupação } \\
\hline entre 1 e 2 anos & -0.1826 & -0.2172 & -0.2556 \\
\hline mais de 2 anos & -0.1550 & -0.2319 & -0.2507 \\
\hline \multicolumn{4}{|l|}{ jornada de trabalho } \\
\hline entre 30 e 44 horas & -0.2656 & -0.1683 & -0.2026 \\
\hline mais de 44 horas & -0.2814 & -0.1175 & -0.1649 \\
\hline \multicolumn{4}{|l|}{ Características domicílio } \\
\hline número de membros & -0.1565 & -0.0962 & -0.0730 \\
\hline n. de membros ao quadrado & 0.0118 & 0.0069 & 0.0051 \\
\hline proporção de crianças & 0.6638 & 0.5483 & 0.4299 \\
\hline proporção de idosos & 0.5374 & 0.4352 & 0.5006 \\
\hline famílias conviventes & -0.0046 & -0.0985 & 0.0389 \\
\hline chefe mulher & 0.0299 & 0.0051 & 0.0420 \\
\hline idade do chefe & -0.0036 & -0.0018 & -0.0045 \\
\hline idade do chefe ao quadrado & 0.0000 & 0.0000 & 0.0001 \\
\hline chefe casado & -0.0963 & -0.0875 & -0.0395 \\
\hline \multicolumn{4}{|l|}{ Mês de entrevista } \\
\hline fevereiro & 0.7701 & 0.9574 & 0.9701 \\
\hline março & 0.8625 & 1.0599 & 1.1072 \\
\hline abril & 0.8110 & 0.9234 & 1.0390 \\
\hline maio & 0.8314 & 0.9496 & 1.0100 \\
\hline junho & 0.8736 & 0.9826 & 0.9925 \\
\hline julho & 0.9279 & 1.0779 & 1.0592 \\
\hline agosto & 0.9003 & 1.0487 & 1.0610 \\
\hline setembro & 0.7989 & 1.0056 & 1.0799 \\
\hline
\end{tabular}




\begin{tabular}{lccc}
\hline & $\mathrm{LP}=50 \%$ mediana & $\mathrm{LP}=60 \%$ mediana & $\mathrm{LP}=70 \%$ mediana \\
\hline Região Metropolitana & & & 0.3743 \\
Recife & 0.3454 & 0.3411 & 0.1685 \\
Salvador & 0.1468 & 0.2297 & 0.1307 \\
Belo Horizonte & 0.1329 & 0.1520 & -0.1277 \\
Rio de Janeiro & -0.1235 & -0.1283 & 0.0201 \\
Porto Alegre & 0.0810 & 0.0682 & \\
Instrumento & & & 4.6656 \\
status de pobreza habitual & 4.7840 & 4.7239 & -3.3603 \\
intercepto & -3.1502 & -3.2027 & \\
\hline
\end{tabular}

Fonte: Elaboração própria a partir da PME 2004.

Nota: Em negrito, estimadores significativos a $1 \%$. LP = linha de pobreza;

Número de estratos geográficos $=106$;

Número de Unidades Primárias de Amostragem = 2065;

Número de observações $=268586$; Tamanho da população $=1.24 \mathrm{e}+08$. 